\title{
Author Correction: Why free choices take longer than forced choices: evidence from response threshold manipulations
}

\author{
Christoph Naefgen $^{1}$ (1) $\cdot$ Michael Dambacher $^{2} \cdot$ Markus Janczyk $^{1}$
}

Published online: 11 October 2017

(c) Springer-Verlag GmbH Germany 2017

\section{Author Correction: Psychological Research DOI 10.1007/s00426-017-0887-1}

The authors regret that some errors that had been addressed during the proofing process were not corrected by the publisher. Most of these errors are of a stylistic nature and do not change the substance of the article. Please note, however, that the corresponding author's e-mail address is christoph.naefgen@uni-tuebingen.de. We apologize for any inconvenience caused by this.

The online version of the original article can be found under doi:10.1007/s00426-017-0887-1.

Christoph Naefgen

christoph.naefgen@uni-tuebingen.de

1 Department of Psychology, Eberhard Karls University of Tübingen, Schleichstraße 4, 72076 Tübingen, Germany

2 University of Konstanz, Constance, Germany 